\title{
Lyme disease vaccine
}

\author{
Scott A Halperin MD
}

$\mathrm{L}$ yme disease is the most common tick-borne infection in the United States, with more than 12,000 cases reported annually (1). The disease is characterized by a rash (erythema migrans) and various systemic (nervous, cardiac and musculoskeletal) manifestations; clinical manifestations of Lyme disease were reviewed recently (2). Most cases of Lyme disease in the United Sates are reported from the northeastern, mid-Atlantic and upper north central states, and from a part of northwest California. Lyme disease is caused by the spirochete Borrelia burgdorferi, and it is transmitted by the deer tick Ixodes scapularis in the eastern and mid-western states, and Ixodes pacificus in the Pacific coast states. Transmission occurs primarily through bites acquired during the nymphal stage of the life cycle of the ticks, which feed predominantly in the late spring and early summer.

Two vaccines that protect against Lyme disease have been developed; one has been licensed for use in Canada recently. Answers to common questions about the Lyme disease vaccine follow.

\section{IS LYME DISEASE PRESENT IN CANADA?}

Lyme disease is not common in Canada. Although it is not a reportable disease in most provinces, less than 30 cases are reported each year (3). In Canada, Lyme disease can be acquired in areas where the tick vector is well established. More than half of the cases of Lyme disease from these areas, and virtually all of the cases from nonendemic areas, can be linked epidemiologically to travel to a highly endemic area of the United States.

\section{WHERE ARE THE TICKS THAT TRANSMIT LYME DISEASE LOCATED IN CANADA?}

Not all ticks can transmit Lyme disease. The common dog tick (Dermacentor variabilis) is not a capable vector for the Lyme disease spirochete. Only the deer tick (I scapularis and I pacificus) is involved in the life cycle of $B$ burgdorferi, and it transmits the disease. Although I scapularis has been found in all provinces from Saskatchewan to the east, and I scapularis was demonstrated to be carrying $B$ burgdorferi in some of these ticks, most ticks have been adult females most likely brought to Canada on migratory birds and have not undergone their full life cycle in Canada (4-7). In fact, I scapularis is established (having larva, nymph and adult stages present) only in the Long Point peninsula and Point Pelee National Park, both on Lake Erie in Ontario, whereas I pacificus undergoes its full reproductive cycle in Canada only in the Fraser River delta, the Gulf Islands and Vancouver Island of British Columbia (8).

\section{IS A LYME DISEASE VACCINE AVAILABLE IN CANADA?}

At present, one Lyme disease vaccine (LYMErix, SmithKline Beecham, Oakville, Ontario) is licensed for use in Canada. A second Lyme disease vaccine (ImuLyme, Aventis Pasteur, Toronto, Ontario) is not yet licensed in Canada. Both vaccines use recombinant $B$ burgdorferi lipidated outer surface protein A (rOspA) to induce protective antibodies. The following information refers to LYMErix, which has been approved for use in Canada, although reported results with ImuLyme are similar (9).

\section{IS LYME DISEASE VACCINE EFFECTIVE?}

LYMErix was compared with placebo in an endemic area in 10,936 healthy individuals who were given three doses of the vaccine at 0 months, one month and 12 months (10). In the year after two doses of vaccine were given, symptomatic, laboratory-confirmed Lyme disease occurred in 22 LYMErix recipients and 43 placebo recipients (vaccine efficacy $49 \%$, $95 \%$ CI $15 \%$ to $69 \%$ ). After the third dose was administered at 12 months, Lyme disease was diagnosed in 16 vaccine recipients and 66 placebo recipients giving a vaccine efficacy of $76 \%$ (95\% CI $58 \%$ to $86 \%$ ).

\section{IS LYME DISEASE VACCINE SAFE?}

In the prelicensure efficacy study (10), LYMErix recipients had more frequent reports at the injection sites than placebo recipients of soreness $(24.1 \%$ compared with $7.6 \%$, respectively), erythema (1.8\% compared with $0.5 \%)$ and swelling ( $0.9 \%$ compared with $0.2 \%)$. Systemic adverse events were less

All material presented in Paediatric Infectious Disease Notes has been reviewed by the Canadian Paediatric Society Board of Directors Department of Pediatrics, IWK-Grace Health Centre, Halifax, Nova Scotia

Correspondence: Infectious Diseases and Immunization Committee, Canadian Paediatric Society, 2204 Walkley Road, Suite 100, Ottawa, Ontario K1G 4G8. Telephone 613-526-9397, fax 613-526-3332, web site www.cps.ca 
commonly reported, and they were more common after the use of LYMErix than placebo (ie, fever $2.0 \%$ compared with $0.8 \%$; myalgia $3.2 \%$ compared with $1.8 \%$; influenzae-like illness $2.0 \%$ compared with $1.1 \%$ ). Adverse events usually were reported in the first $48 \mathrm{~h}$ after immunization, and lasted a median of three days.

\section{WHO SHOULD GET LYME DISEASE VACCINE?}

Vaccination should only be considered as an adjunctive measure to avoid Lyme disease. Personal control measures such as avoiding tick-infested areas, covering exposed skin, wearing light coloured clothing to allow easier observation and removal of ticks, examination for ticks each evening, and tick repellents are all important measures in preventing Lyme disease.

Lyme disease vaccine should be given to individuals who are 15 years of age or older, and who, because of their recreational activity or occupation, cannot avoid exposure to ticks in an endemic area. A risk assessment should be made to determine the advisability of being immunized (1).

- Persons at high risk are those who live in, or visit, areas of high or moderate risk, and who engage in activities (eg, recreational, occupational and property maintenance) that result in frequent or prolonged exposure to a tick-infested habitat. Vaccine should be considered for these individuals.

- Persons at moderate risk are those who live in, or visit, areas of high or moderate risk, and who are exposed to a tick-infested habitat but whose exposure is neither frequent nor prolonged. Lyme disease vaccine may be considered for these individuals.

- Persons at low or no risk are those who live in areas of low or no risk, or those who live in, or visit, areas of moderate or high risk but have minimal or no exposure to Lyme disease vector ticks.

\section{WHO SHOULD NOT BE GIVEN LYME DISEASE VACCINE?}

Lyme disease vaccine should not be given to persons who are at low or no risk of acquiring the disease; most Canadians fit into this category. In addition, Lyme disease vaccine should

\section{REFERENCES}

1. Recommendations for the use of Lyme disease vaccine: Recommendations of the Advisory Committee on Immunization Practices (ACIP). MMWR Morb Mortal Wkly Rep 1999;48:1-25.

2. Nadelman RB, Wormser GP. Lyme boreliosis. Lancet 1998;352:557-65.

3. Laboratory Centre for Disease Control. Consensus Conference on Lyme Disease. Can J Infect Dis 1991;2:49-54.

4. Banerjee SN, Christensen CI, Scott JD. Isolation of Borrelia burgdorferi on mainland Ontario. Can Commun Dis Rep 1995;21:85-6.

5. Morshed MG, Scott JD, Banerjee SN, et al. First isolation of Lyme disease spirochete, Borrelia burgdorferi from blacklegged tick Ixodes scapularis, removed from a bird in Nova Scotia, Canada. Can Commun Dis Rep 1999;25:153-5

6. Lindsay R, Artsob H, Galloway T, Horsman G. Vector of Lyme borreliosis Ixodes scapularis identified in Saskatchewan. Can Commun Dis Rep 1999;25:81-3. not be given during pregnancy or to children under 15 years of age (until safety data are available). There are no data on the safety or efficacy of Lyme disease vaccine in people with immunodeficiencies. Lyme disease vaccine should not be given to individuals with a history of treatment-resistant Lyme disease because of the association of this condition with abnormal immune reactivity to OspA.

\section{HOW MANY DOSES OF VACCINE ARE NEEDED? IS A BOOSTER NECESSARY?}

Three doses of Lyme disease vaccine are required to provide optimal protection. The first two doses (at 0 months and one month) should be timed so that maximal protection (one month after the second dose) immediately precedes the beginning of the tick's nymphal stage feeding season (April). This ensures that the third dose at 12 months immediately precedes the subsequent tick season. It is not known yet whether additional booster doses will be required for subsequent seasons.

\section{WHY NOT IMMUNIZE EVERYONE?}

The risk of acquiring Lyme disease is so low in Canada that universal immunization with Lyme disease vaccine is not advisable. In fact, it would not be cost beneficial to immunize everyone even in highly endemic communities in the United States (11). Therefore, a risk assessment that analyzes the likelihood of exposure to Lyme disease provides the most cost effective method of using this vaccine.

\section{WHERE CAN I GET MORE INFORMATION ABOUT LYME DISEASE AND LYME DISEASE VACCINE?}

The risk of acquiring Lyme disease, even in endemic areas of the United States, is very localized (ie, relating to communities rather than counties or states). The most up-to-date information about areas of risk can be obtained from local public health authorities. Detailed American recommendations for the use of Lyme disease vaccine have been published in the Morbidity and Mortality Weekly Report (1); Canadian guidelines from the National Advisory Committee on Immunization will be published soon in the Canada Communicable Disease Report. The product monograph should be consulted for specific prescribing information.

7. Banerjee S, Banerjee M, Scott J, Lankester M, Kubinec J. Isolation of Borrelia burgdorferi - Thunder Bay District, Ontario. Can Commun Dis Rep 1996;22:138-40.

8. Lindsay R, Barker I. Distribution of Ixodes pacificus and Ixodes scapularis re concurrent Babesiosis and Lyme disease. Can Commun Dis Rep 1998;24:121-2.

9. Sigal LH, Zahradnik JM, Lavin P, et al. A vaccine consisting of recombinant Borrelia burgdorferi outer-surface protein A to prevent Lyme disease. Recombinant Outer-Surface Protein A Lyme Disease Vaccine Study Consortium. N Engl J Med 1998;339:216-22.

10. Steere AC, Sikand VK, Meurice F, et al. Vaccination against Lyme disease with recombinant Borrelia burgdorferi outer-surface lipoprotein A with adjuvant. Lyme Disease Vaccine Study Group. N Engl J Med 1998;339:209-15.

11. Meltzer MI, Dennis DT, Orloski KA. The cost effectiveness of vaccinating against Lyme disease. Emerg Infect Dis 1999;5:321-8. 


\section{Paediatric Infectious Disease Notes}

\section{INFECTIOUS DISEASES AND IMMUNIZATION COMMITTEE}

Members: Drs Upton Allen, The Hospital for Sick Children, Toronto, Ontario; François Boucher, Département de pédiatrie, Centre Hospitalier Universitaire de Québec, Pavillon CHUL, Sainte-Foy, Québec; H Dele Davies, Division of Infectious Diseases, Alberta Children's Hospital, Calgary, Alberta; Gilles Delage, Laboratoire de santé publique du Québec, Sainte-Anne-de-Bellevue, Québec (chair); Joanne Embree, The University of Manitoba, Winnipeg, Manitoba; Mireille Lemay, Department of Infectious Diseases, Sainte-Justine Hospital, Montréal, Québec; Charles Morin, Complexe hospitalier Sagamie, Chicoutimi, Québec (director responsible); David Speert, Division of Infectious and Immunological Diseases, University of British Columbia, Vancouver, British Columbia; Ben Tan, Division of Infectious Diseases, Royal University Hospital, University of Saskatchewan, Saskatoon, Saskatchewan

Consultants: Drs Noni MacDonald, Faculty of Medicine, Dalhousie University, Halifax, Nova Scotia; Victor Marchessault, Cumberland, Ontario Liaisons: Drs Susan King, Division of Infectious Diseases, The Hospital for Sick Children, Toronto, Ontario (Canadian Paediatric AIDS Research Group); Scott A Halperin, Department of Pediatrics, IWK-Grace Health Centre, Halifax, Nova Scotia (IMPACT, and principal author); Monique Landry, Direction de la santé publique de Laval, Laval, Québec (Public Health); Larry Pickering, Centers for Disease Control and Prevention, Atlanta, Georgia (American Academy of Pediatrics); John Waters, Alberta Health, Edmonton, Alberta (Epidemiology)

This article also appears in Paediatr Child Health 2000;5(4):203-205. 


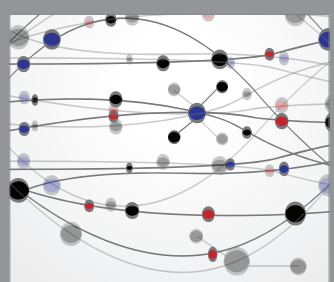

The Scientific World Journal
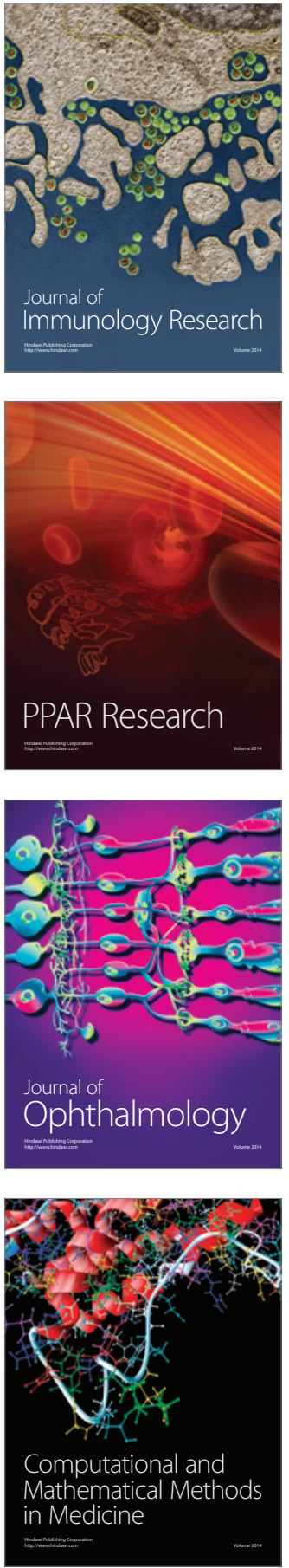

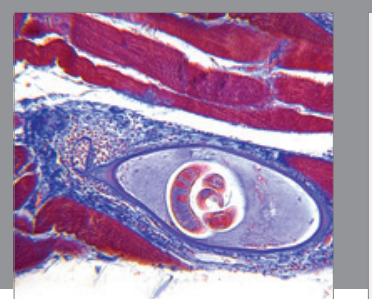

Gastroenterology Research and Practice

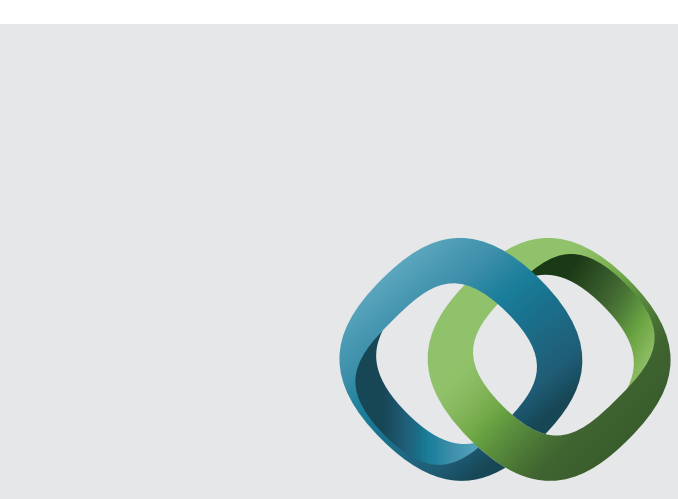

\section{Hindawi}

Submit your manuscripts at

http://www.hindawi.com
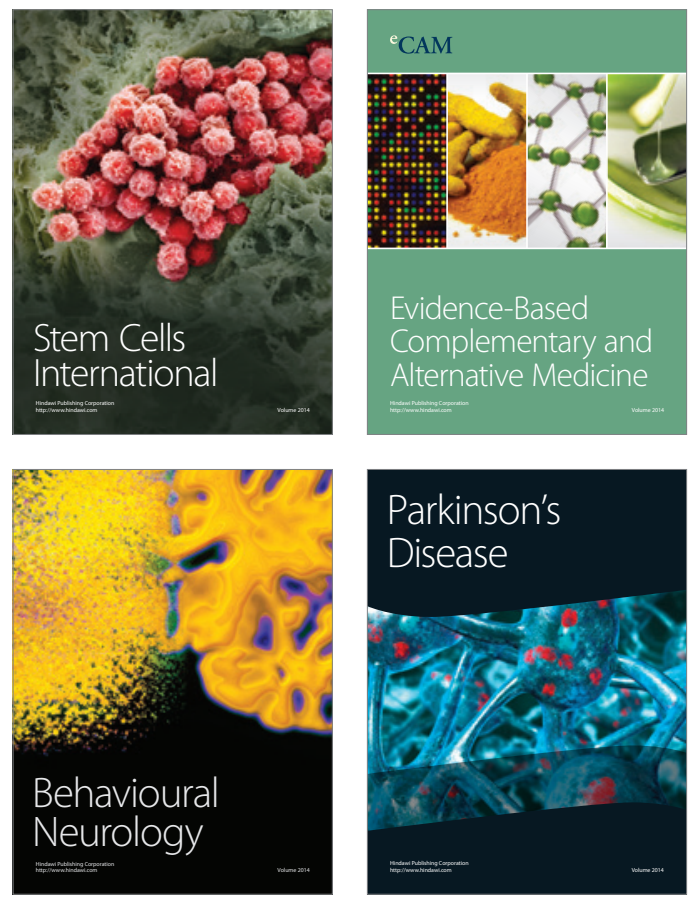
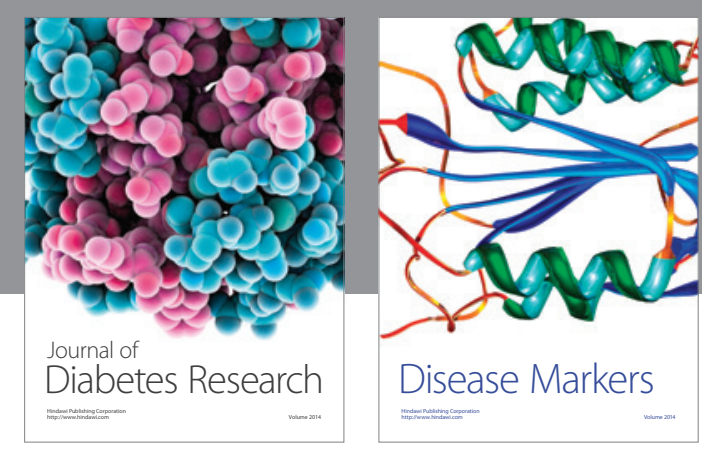

Disease Markers
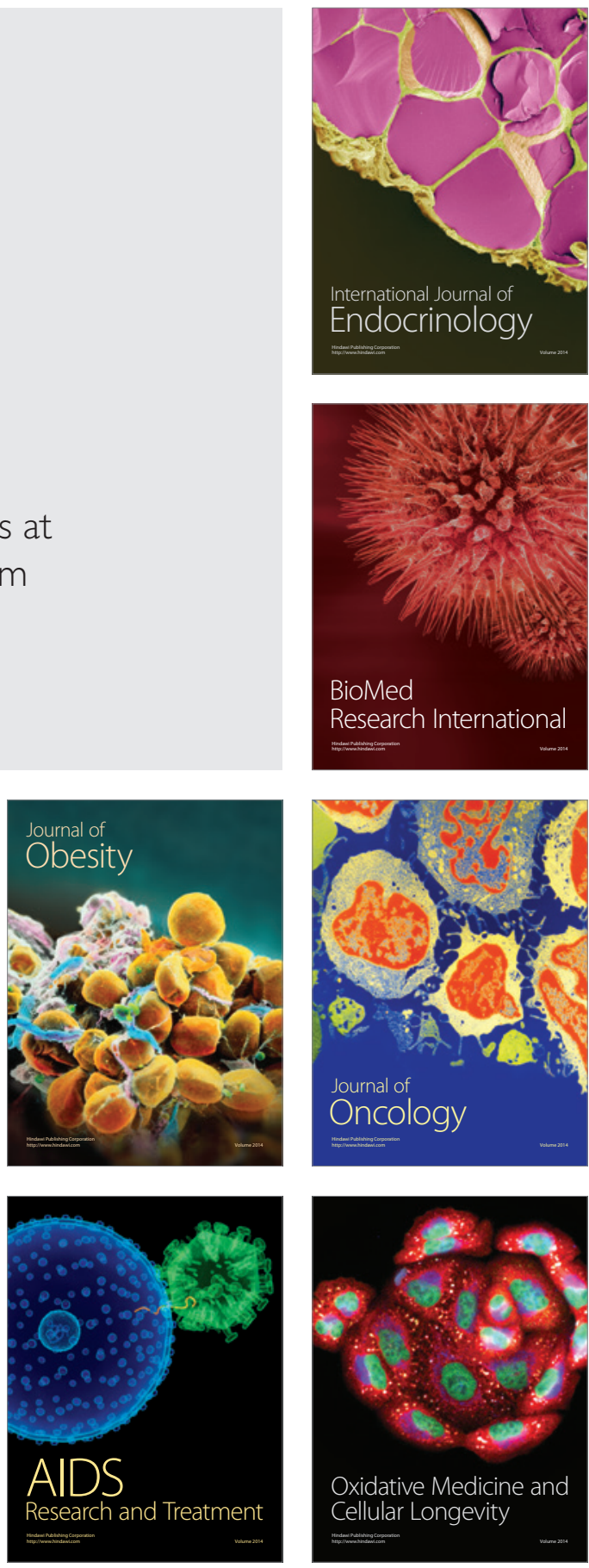